\title{
Effects of electrostatic charge on the pathogenicity of chrysotile asbestos
}

\author{
J M G DAVIS, R E BOLTON, A N DOUGLAS, A D JONES, T SMITH \\ From the Pathology Branch, Institute of Occupational Medicine, Edinburgh EH8 9SU, UK
}

\begin{abstract}
Two groups of 48 rats of the AF/HAN strain were exposed for one year to respirable dust clouds of UICC chrysotile asbestos at a dose level of $10 \mathrm{mg} / \mathrm{m}^{3}$. One group was treated with dust carrying the normal electrostatic charge produced during dust generation, whereas the other was exposed to dust discharged by exposure to ionising radiation from a thallium-204 source. After dusting most animals were retained for their full life span. At the end of the dusting period those animals treated with normally charged dust had significantly more chrysotile retained in their lungs than animals exposed to discharged dust. Subsequently, animals treated with normally charged dust developed more pulmonary fibrosis and more pulmonary tumours. These findings suggest that the charge carried by airborne fibres should be taken into account when considering the health risks from exposure to chrysotile. Highly charged fibres are more likely to be deposited in lung tissue and thus constitute a greater hazard.
\end{abstract}

Airborne mineral dust particles can carry considerable electrostatic charge which is usually gained during the process of dust dispersion. This property has been examined in experimental studies by a number of workers $^{1-3}$ and also in the factory environment ${ }^{4}$ (Alkosenko, International Conference on Harmful Dust in Mines, Gottwaldor 1970). Much of the published work relates to non-fibrous dusts (particularly coal). Less has been published about fibrous dusts, but the information available suggests that fibres can carry a higher individual charge than compact particles of equivalent aerodynamic size. ${ }^{5}$

The available overall evidence from inhalation studies suggests that highly charged particles deposit more readily in lung tissue and this electrostatic enhancement of lung deposition is greater for fibrous than for non-fibrous dusts. This experimental evidence is consistent with the deposition theory based on the effects of electrical image forces, ${ }^{6}$ which also suggests that the magnitude of this effect is proportional to fibre length. In most circumstances the aerosol contains about equal numbers of positively charged particles and negatively charged particles.

Studies with human volunteers have shown that the pulmonary deposition of inhaled aerosols of isometric particles may be considerably increased by the electrostatic charge carried by the individual

Accepted 11 May 1987 particles $^{7-9}$ and similar results have been obtained in experimental animals. ${ }^{111}$

In further studies the deposition of amosite and chrysotile asbestos, both charged and discharged, was examined in rats. ${ }^{12}{ }^{13}$ It was reported that rats exposed for six weeks to a charged cloud of amosite had $24 \%$ more dust in their lungs than animals exposed to a similar dust cloud that had been discharged by passage through a thallium-204 source of $\beta$ particles. For chrysotile the effect was even more pronounced, with animals exposed to charged dust retaining double the amount of dust at the end of the dusting period than those exposed to a discharged dust cloud. The results indicated that the enhancement of deposition associated with electrostatic charge takes place in the alveolar region of the lung.

The present study was undertaken to examine the deposition of charged and discharged chrysotile clouds over longer periods than in previous studies and to determine whether or not differences in the amounts of retained dust were sufficient to produce differences in pulmonary pathology.

\section{Materials and methods}

DUST GENERATION AND MONITORING

The dust inhalation phase of this study was undertaken in inhalation chambers of the type described 
previously. ${ }^{14}$ The animals were housed, fed, and watered in the chamber throughout the exposure phase.

The dust clouds were generated using modified Timbrell fibrous dust dispensers. ${ }^{14}$ Is To reduce the electrostatic charge the dispersed dust from one dispenser was exposed to ionising radiation from a thallium-204 source of $\beta$ particles before entering into the exposure chamber. The dust from the other dispenser was ducted directly through an identical set of pipework to the other exposure chamber.

The respirable dust mass concentrations were measured daily using the Casella MRE 113A gravimetric sampler ${ }^{16}$ with samples taken for the full seven hours of dust exposure and on each of the 224 days of dusting. The total dust concentrations were measured using open face $50 \mathrm{~mm}$ diameter filter holders facing downwards with seven hour samples collected daily on ten days at a flow rate of $2 \mathrm{l} / \mathrm{min}$.

The fibre number concentrations and size distributions were assessed from Nuclepore filter and membrane filter snatch (or very short period) samples collected using $25 \mathrm{~mm}$ diameter Gelman heads (open face filters) on 85 separate days. The membrane filter samples were examined using phase contrast optical microscopy $(\mathrm{PCOM})$ at $\times 600$ magnification, and counts made of fibres with length greater than $5 \mu \mathrm{m}$, aspect ratio greater than 3:1, and diameter less than 3 $\mu \mathrm{m}$. The counting procedures are essentially the same as those used routinely for assessing membrane samples from occupational environments. ${ }^{1718}$ The Nuclepore samples were examined using scanning electron microscopy (SEM) to produce fibre size distributions for fibres longer than 0.4 microns, with measurements taken from the video screen at $\times 10000$ magnification. The minimum length specified for the measurements corresponds to a detection limit of $0.1 \mu \mathrm{m}$ diameter for fibres with approximately $3: 1$ aspect ratio.

As an aid to achieving the target respirable dust concentration, the differential pressure across a membrane filter sample was monitored as it rose in proportion to the amount of dust collected during the day. The dust generation system and chamber ventilation were adjusted appropriately in response to the rise in differential pressure and in response to the dust concentration achieved on the previous days.

The magnitude of the electrostatic charge carried by the fibres was measured using an electrostatic elutriator and an optical particle counter (Royco Instruments, Inc) as described elsewhere..$^{1213}$ The elutriator consisted of four rectangular channels, similar to that of a Casella type MRE 113A respirable dust sampler, modified to provide a uniform electric field between adjacent plates by grounding three of the plates and applying an electric potential to the other two. Measurements were made of the fibre penetration as a function of the applied voltage, comparing the number of fibres penetrating the electrified elutriator with those penetrating the same elutriator at earth potential. In this study the penetration function was determined by recording the changing rate of counts from an optical particle counter as the voltage applied to the elutriator was increased. In the previous study it was shown that equivalent descriptions of the penetration function (from which the charge is calculated) may be obtained either from counts produced by an optical particle counter or from counts produced manually by optical microscopy from membrane filters. ${ }^{13}$

The magnitude of the charge levels was determined from the penetration function measured in terms of counts. As a semiquantitative check on the maintenance of the appropriate charge levels on the dusts in each exposure chamber, the same type of electrostatic elutriator was used regularly at fixed flow rate and applied voltage in each chamber. The dust penetrating through the elutriator was collected on membrane filters and assessed gravimetrically. The amount of dust penetrating was then compared daily with the mass concentration in the chamber, and these comparisons give a regular indication of substantial differences in charge level between the two dust exposures.

\section{ANIMAL INHALATION STUDIES}

For the inhalation studies, groups of 48 SPF male Wistar rats of the AF/HAN strain were exposed to chrysotile dust clouds (UICC chrysotile " $A$ ") either charged or discharged, for seven hours each day, five days a week for a total of 224 days during a period of 12 months. The animals were 10 weeks old at the start of dusting. Two batches of 36 and 25 undusted animals, maintained within the same unit, were available for comparison as controls.

Four animals from each experimental group were killed at the end of the 12 months dusting period and four more were killed six months later. The remaining animals were left for their full life span except that the study was terminated when the number of survivors in one group had dropped to six. Estimations of early fibrotic lesions were limited to the small groups of animals from the first two killing dates. For the more advanced alveolar interstitial fibrosis occurring in the oldest animals, however, all those dying within two months of the final killing date were included. In practice this produced groups of 13 animals treated with the normal chrysotile dust cloud and 16 animals dusted with the discharged chrysotile cloud. Lungs from all animals in this study were examined histologically for the presence of neoplasms. Samples were also taken for histology from all other organs 
showing macroscopic abnormalities.

Tissues used for histological examination were fixed with Karnovsky's fixative and embedded in paraffin wax. Lungs were fixed by inflation at a standard pressure of $30 \mathrm{~cm}$ of fixative. Subsequently, the trachea were ligated and the lungs excised and immersed in fixative. Sections were cut in the coronal plane at $1 \mathrm{~mm}$ intervals and were stained by either haematoxylin and eosin, Van Giesen's method for collagen, or Gordon and Sweet's stain for reticulin.

Measurement of pulmonary fibrosis was undertaken by methods similar to those previously published ${ }^{19}$ except that an electronic image analyser (Graphic Information Systems Limited, GDS1) was available for use in conjunction with the light microscope. ${ }^{20}$ Single lung sections were examined and the sections selected to contain the maximum area of lung parenchyma. As previously described, interstitial fibrosis was estimated using a $\times 2$ microscope objective lens and is expressed as a percentage of total lung tissue area. Peribronchiolar lesions are more numerous and smaller and so the lung tissue was scanned with an eyepiece graticule covering a tissue area of $2.92 \mathrm{~mm}^{2}$ and divided into 100 squares. $A \times 4$ objective lens was used. Peribronchiolar lesions were recorded as the percentage of squares containing lesions of this type.

Lung dust estimations were performed on animals from the first two killing dates. Only the left lung was used so that the right lung was available for histological studies. (Studies in this laboratory have shown that the ratio of dust content between left and right lungs after experimental inhalation of fibrous dust such as asbestos in rats is approximately 0.6:1, and this correction factor was therefore used to estimate the total pulmonary dust burden for each animal.) Dust retained in the lungs was recovered by a low temperature plasma ashing process using a Nanotech P100 apparatus. After tissue ashing, the chrysotile residues were washed in distilled water at room temperature before estimations of the amounts of retained fibre were made using infrared spectroscopy techniques. ${ }^{21}$

\section{STATISTICAL TECHNIQUES}

Survival functions for each experimental group were estimated using the product limit method. ${ }^{22}$ The survival curves for the different series were tested for homogeneity using the Generalised Wilcoxon (Breslow) statistic in the statistical package BMDP. ${ }^{23}$ To compare the overall mortality of the two groups of animals, the death of an animal as part of a planned kill was treated as a censoring event and all other deaths were treated as responses. Incidence of tumours in particular sites was also compared by estimating survival functions. All deaths of animals without non- pulmonary tumours were recorded as censoring events, whereas non-pulmonary tumours were treated as responses irrespective of whether the death was planned or unplanned.

Comparisons of levels of pulmonary fibrosis and lung dust burdens were made using the generalised linear models facilities in the statistical package GENSTAT. ${ }^{24}$ The proportion of lung area with interstitial fibrosis was logarithmically transformed before analysis using conventional analysis of variance methods. The proportion of the points on the lung with peribronchial fibrosis was analysed by logistic regression techniques. Lung dust burdens were compared by analysis of variance.

\section{Results}

\section{ESTIMATION OF DUST CLOUDS}

\section{Dust cloud mass}

The mean mass concentrations for respirable chrysotile dust during the exposure period of 224 days was $9.9 \mathrm{mg} / \mathrm{m}^{3}$ for both charged and discharged dust clouds (table 1). The MRE sampler measuring the normally charged dust cloud, however, was found to have been operating at slightly too high a flow rate between days 160 and 200 and since these figures had been used to control the dust clouds, the dust levels for the normally charged cloud had in fact been slightly too low. Although the magnitude of this error was only sufficient to reduce the mean dust cloud figures by less than $3 \%(0.3 \mathrm{mg})$ over the full duration of the study, it was decided to equilibrate the dust exposures by slightly increasing the respirable mass of the normally charged dust cloud over the last 24 days of the exposure period.

\section{Fibre numbers and dimensions}

The mean number of fibres ( $>5 \mu \mathrm{m}$ in length by PCOM) in the two dust clouds was $2560 / \mathrm{ml}$ for the normal dust cloud and $2670 / \mathrm{ml}$ for the discharged dust cloud (table 1). The fibre size distributions for the two dust clouds, as measured by both PCOM and SEM, are illustrated in figs 1 and 2 . The length and diameter

Table 1 Airborne concentrations of dust by mass and fibre number for the normally charged and discharged chrysotile clouds

\begin{tabular}{lcc}
\hline Airborne concentration & Normal chrysotile & Discharged chrysotile \\
\hline $\begin{array}{c}\text { Total dust mass }\left(\mathrm{mg} / \mathrm{m}^{3}\right. \\
\text { of air) }\end{array}$ & 11.0 & 11.7 \\
$\begin{array}{l}\text { Respirable dust mass } \\
\quad\left(\mathrm{mg} / \mathrm{m}^{3} \text { of air) }\right.\end{array}$ & 9.9 & 9.9 \\
$\begin{array}{c}\text { No of fibres }>5 \mu \mathrm{m} / \mathrm{ml} \\
\text { counts by PCOM }\end{array}$ & 2560 & 2670 \\
\end{tabular}

PCOM = Phase contrast optical microscopy. 


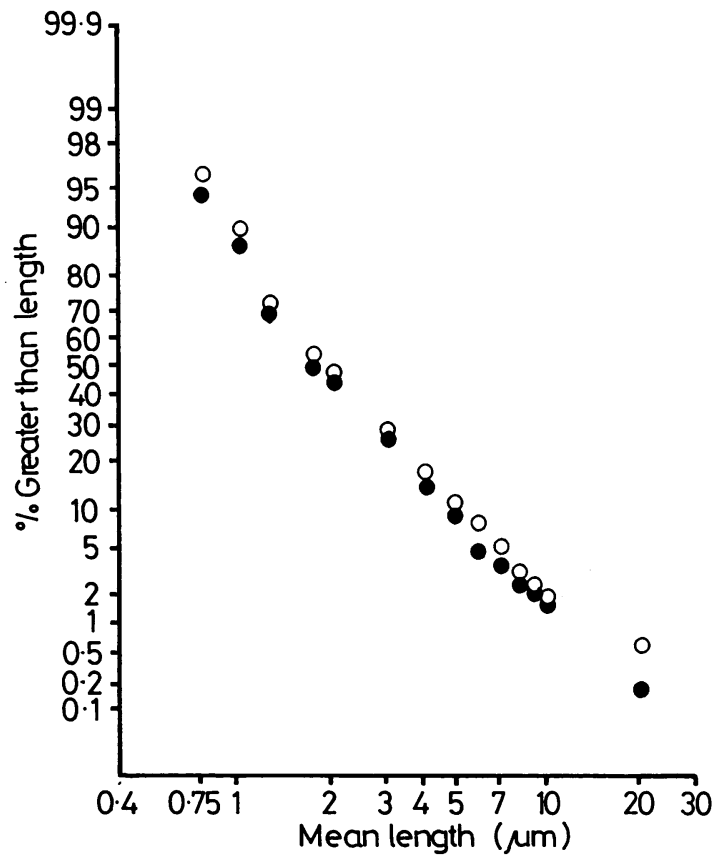

Fig 1 Fibre length distributions of charged and discharged chrysotile dust clouds. SEM sizing at 10000 magnification. Fibres sized have length $>0.4 \mu \mathrm{m}$, diameter $<3 \mu \mathrm{m}$, and aspect ratio $>3: 1.0=$ Discharged dust cloud ( 500 fibres sized). $\bigcirc=$ Normally charged dust cloud ( 300 fibres sized).

distributions shown for the two dusts are almost identical and fibre dimensions had obviously not been changed by the discharging process.

Table 2 Magnitude of charge on airborne chrysotile asbestos

\begin{tabular}{lc}
\hline & $\begin{array}{l}\text { Median magnitude of charge } \\
\text { per unit length of fibre }\end{array}$ \\
\hline Dust type and source & \\
\hline $\begin{array}{l}\text { Laboratory studies } \\
\text { Charged UICC chrysotile } \\
\text { (present study) }\end{array}$ & 13 \\
$\begin{array}{l}\text { Discharged UICC chrysotile } \\
\text { (present study) }\end{array}$ & 2 \\
Charged UICC chrysotile (Jones et \\
$\begin{array}{l}\text { al, 1983) } \\
\text { Discharged UICC chrysotile (Jones } \\
\text { et al, 1983) }\end{array}$ & 10 \\
Factory studies (Johnston et al, 1985): & \\
Factory I & \\
Carding & 13 \\
Spinning & 10 \\
Weaving & 10 \\
Factory 2 & 8 \\
Carding & 11 \\
Spinning & 5 \\
Spinning (damp) & 6 \\
Weaving & \\
\hline
\end{tabular}

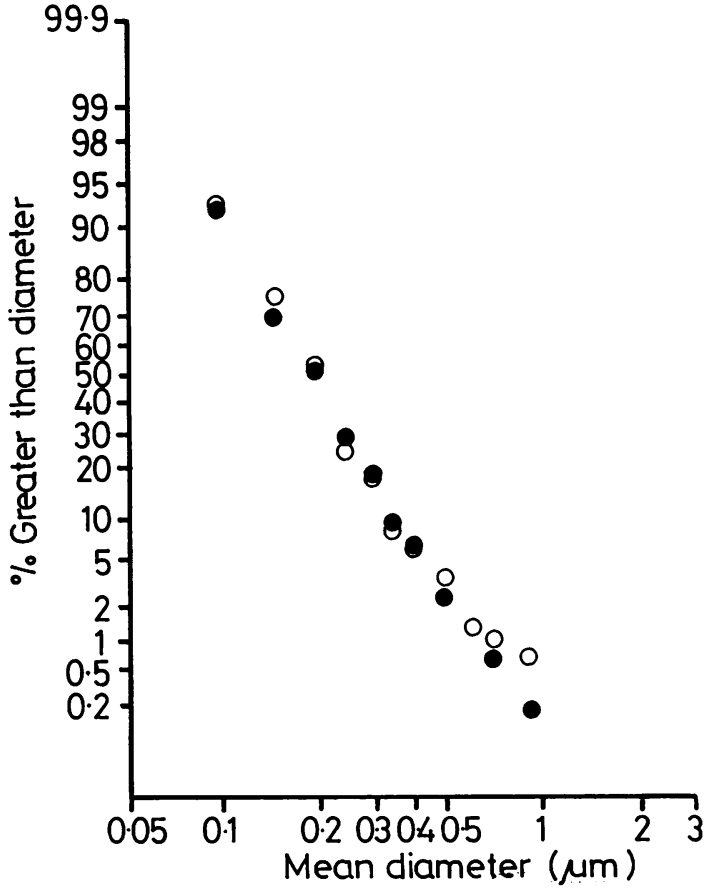

Fig 2 Fibre diameter distributions of charged and discharged chrysotile dust clouds. SEM sizing at 10000 magnification. Fibres sized have length $>0.4 \mu \mathrm{m}$, diameter $<3 \mu \mathrm{m}$, and aspect ratio $>3: 1$. = Discharged dust cloud ( 500 fibres sized) $. \bigcirc=$ Normally charged dust cloud (300 fibres sized).

\section{Electrostatic charge}

Table 2 shows the median magnitude of charge per unit length of fibre for the two dust clouds in this study, together with other results from previous studies with chrysotile, both in the laborator $y^{13}$ and in asbestos textile factories. ${ }^{5}$ In the present long term inhalation studies the discharging process had reduced the median magnitude of the charge per unit length of fibre from 13 electrons $/ \mu \mathrm{m}$ to 2 electrons $/ \mu \mathrm{m}$.

\section{PATHOLOGICAL FINDINGS}

The median survival times for animals treated with normally charged or discharged chrysotile were 28.8 and 29.5 months respectively. These figures are not significantly different. Nevertheless, the two control groups of animals survived rather better with median survival times of 33.2 and 31.5 months respectively and these figures are both significantly better than the groups treated with chrysotile $(\mathrm{p}<0.001)$.

Both groups of rats treated with chrysotile developed the same types of pathological change previously reported in similar inhalation studies from this Institute. ${ }^{19202526}$ At the end of the 12 month 


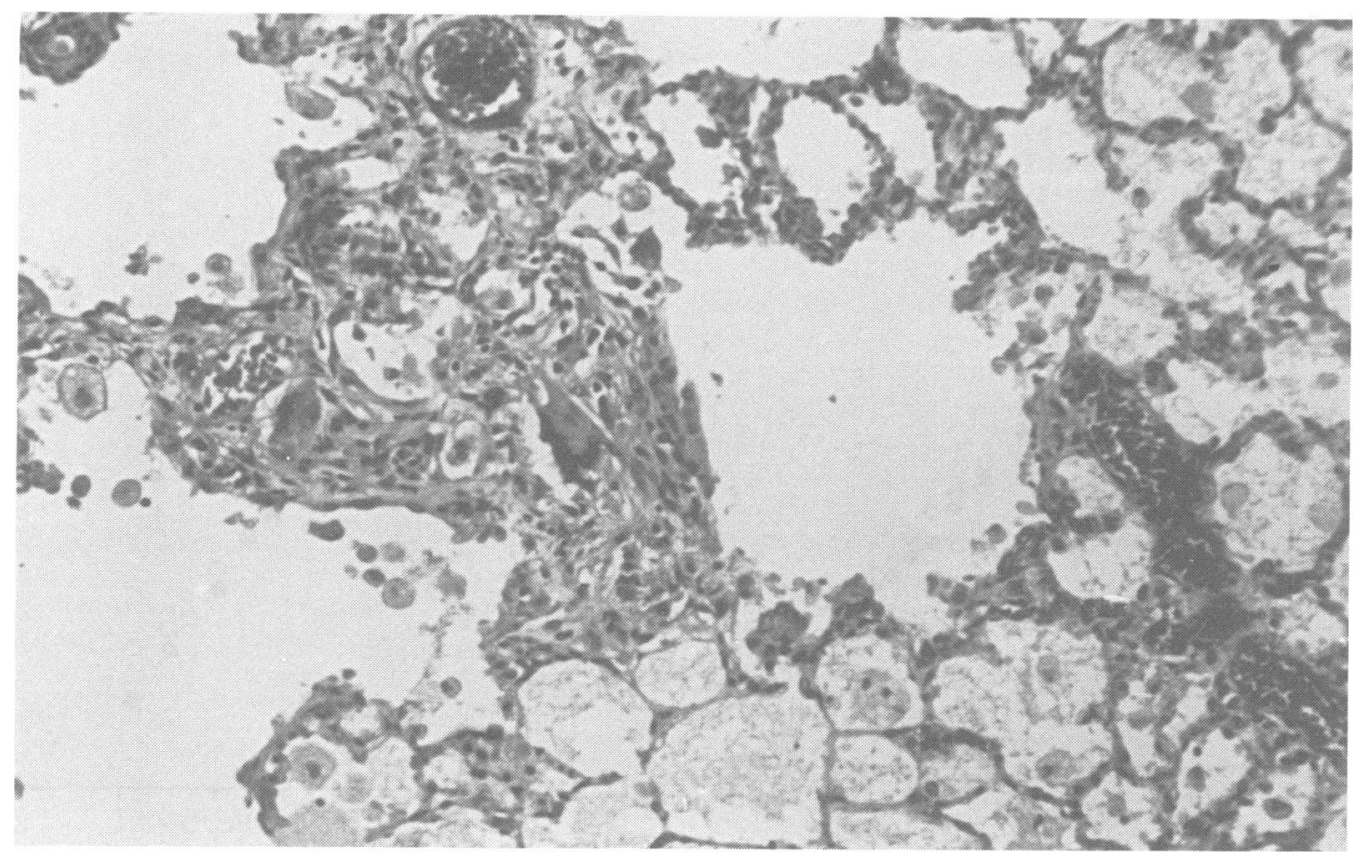

Fig 3 A focus of loose granulation tissue in walls of respiratory bronchioles from lungs of rat killed at end of 12 months inhalation of normally charged chrysotile. Magnification $\times 250$.

dusting period the main lesions present were deposits of granulation tissue around the terminal and respiratory bronchioles (fig 3 ). This granulation tissue consisted mainly of macrophages and fibroblasts but some foreign body giant cells were also present. At the end of the dusting period there was pronounced reticulin staining in the peribronchial deposits, although relatively little collagen could be shown by Van Gieson's stain. In lesions from older animals, however, collagen staining increased in intensity. As shown in table 3 the proportion of lung tissue containing areas of peribronchial fibrosis (PBF), at the end of the dusting period, was higher in animals treated with a normally charged chrysotile cloud than in animals that had inhaled discharged dust $(\mathrm{p}<0.01)(\mathrm{t}=4.7$ with 12 degrees of freedom). During the subsequent six months the areas of PBF were reduced in both treatment groups, partly because there appeared to be some contraction of the loose granulation tissue originally formed. This reduction, however, was not significantly different between the two treatment groups. In general from about 18 months onwards, areas of lung tissue in animals exposed to the two chrysotile clouds showed a progressive thickening of alveolar septa. In its earliest form this thickening was caused almost entirely by hyperplasia of type II pneumocytes but later there was considerable deposition of reticulin and eventually collagen in the septal

Table 3 Mean levels of pulmonary fibrosis produced by normally charged and discharged chrysotile dust. (Figures in parentheses are ranges)

\begin{tabular}{|c|c|c|c|c|c|c|c|c|}
\hline \multirow[b]{2}{*}{$\begin{array}{l}\text { Time after start } \\
\text { of exposure } \\
\text { (months) }\end{array}$} & \multicolumn{3}{|c|}{ Normal chrystotile } & \multicolumn{3}{|c|}{ Discharged chrysotile } & \multirow{2}{*}{$\frac{\text { Control group } 1}{27-29}$} & \multirow{2}{*}{$\begin{array}{l}\text { Control group } 2 \\
27-29\end{array}$} \\
\hline & 12 & 18 & $27-29$ & 12 & 18 & $27-29$ & & \\
\hline $\begin{array}{l}\text { No of rats } \\
\text { examined }\end{array}$ & 4 & 4 & 13 & 4 & 4 & 16 & 9 & 13 \\
\hline $\begin{array}{l}\text { Peribronchial } \\
\text { fibrosis }\end{array}$ & $\begin{array}{l}16 \cdot 6 \\
(15 \cdot 6-17 \cdot 6)\end{array}$ & $\begin{array}{l}11 \cdot 8 \\
(8 \cdot 9-14 \cdot 3)\end{array}$ & - & $\begin{array}{l}14 \cdot 5 \\
(14 \cdot 1-15 \cdot 1)\end{array}$ & $\begin{array}{l}10 \cdot 0 \\
(9 \cdot 1-11 \cdot 1)\end{array}$ & $\overline{0}$ & 0 & 0 \\
\hline $\begin{array}{l}\text { Interstitial } \\
\text { fibrosis }\end{array}$ & 0 & $\begin{array}{l}1 \cdot 1 \\
(0-3 \cdot 7)\end{array}$ & $\begin{array}{l}12 \cdot 2 \\
(1 \cdot 5-24 \cdot 3)\end{array}$ & 0 & $\begin{array}{l}0 \cdot 3 \\
(0-1 \cdot 3)\end{array}$ & $\begin{array}{l}7.6 \\
(0 \cdot 7-16 \cdot 0)\end{array}$ & $\begin{array}{l}0.5 \\
(0-3 \cdot 0)\end{array}$ & 0 \\
\hline
\end{tabular}




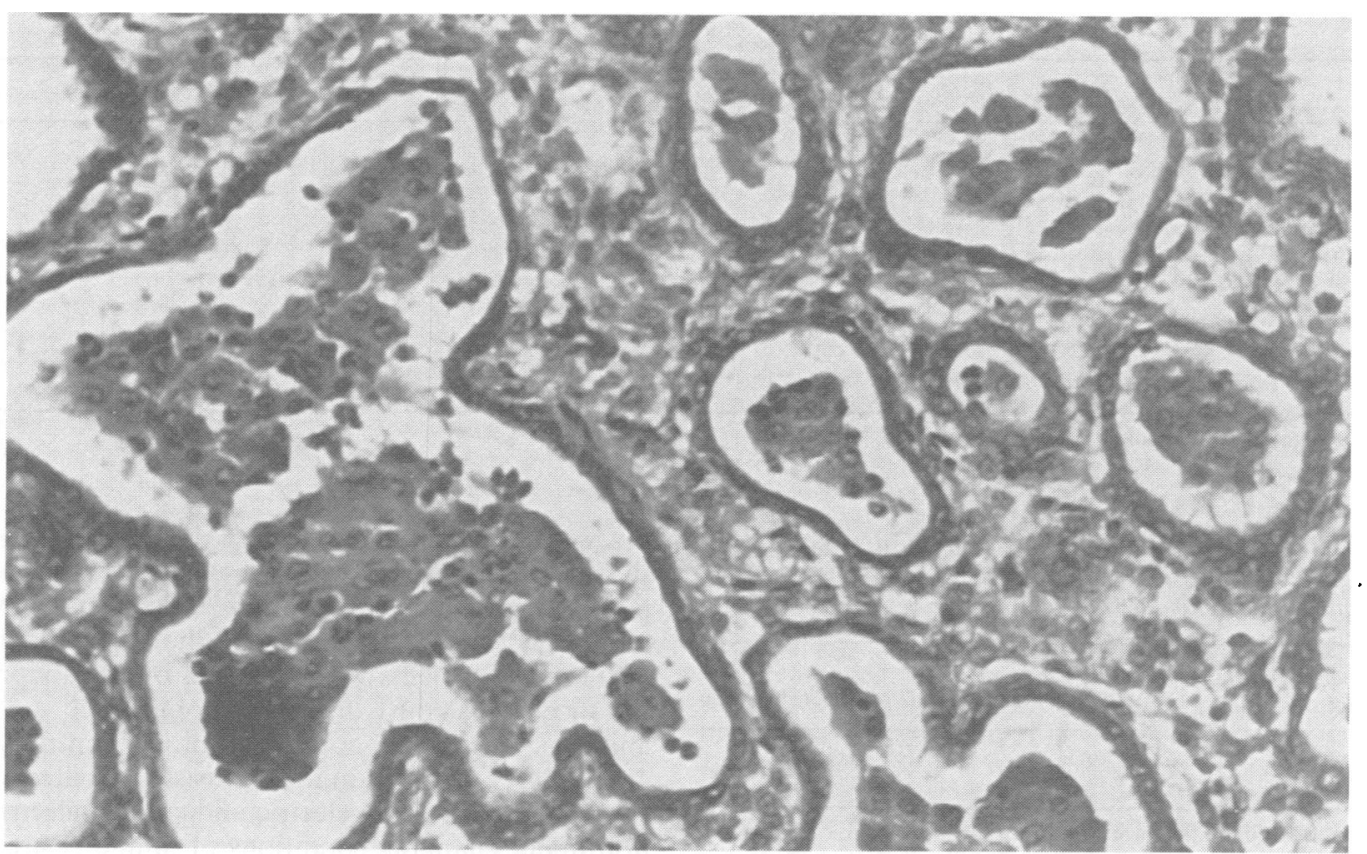

Fig 4 Section of lung tissue from rat killed 19 months after end of 12 months inhalation of "discharged" chrysotile asbestos. Normal architecture has been replaced by a lesion similar to human "honeycombing" where lung spaces no longer all correspond to original alveoli. Honeycomb spaces are lines by cuboidal epithelium and septa between them are thickened with fibrous tissue. Magnification $\times 600$.

walls (fig 4). As shown in table 3, these areas of alveolar interstitial fibrosis became more extensive as the animals aged. In the oldest animals the mean percentage of lung tissue affected with interstitial fibrosis was 12.2 in the rats treated with a normally charged dust cloud and 7.6 in rats that had inhaled discharged chrysotile. Analysis of variance between individual animals indicates, however, that these differences could have arisen by chance. In old control animals very small areas of interstitial fibrosis were occasionally found but the mean percentage of lung tissue affected for these groups was only $0 \cdot 2 \%$.

In some areas of the lungs of animals exposed to chrysotile the interstitial fibrotic element became progressively more pronounced with time but in some lesions hyperplasia of the epithelial cells lining the tissue spaces became more pronounced to produce a pattern of adenomatosis. Pulmonary tumours developed in animals exposed to both charged and discharged chrysotile (table 4). Six pulmonary adenomas and eight carcinomas were found in rats treated with the normally charged dust and four adenomas, six carcinomas, and one mesothelioma were found in those treated with discharged dust. These incidence rates are not significantly different between the two treatment groups (Breslow test statistic 0.561 on $1 \mathrm{df}$ ). Most animals over 2 years of age from both treatment groups had areas of vesicular

Table 4 Numbers of pulmonary tumours and mesotheliomas found in rats treated with normally charged and discharged chrysotile asbestos

\begin{tabular}{lcccc}
\hline & Normal chrysotile & Discharged chrysotile & Control group l & Control group 2 \\
\hline No of rats & 36 & 39 & 36 & 25 \\
Adenoma & 6 & 4 & 1 & 0 \\
Adenocarcinoma & 4 & 4 & 0 & 0 \\
Squamous carcinoma & 4 & 2 & 1 & 0 \\
Pleural inesothelioma & 0 & 1 & 0 & 0 \\
Totals & 14 & 11 & 2 & 0 \\
\hline
\end{tabular}


Table 5 Numbers of tumours occurring at sites other than the lung

\begin{tabular}{|c|c|c|c|c|c|c|c|c|}
\hline & \multicolumn{2}{|c|}{ Normal chrysotile } & \multicolumn{2}{|c|}{ Discharged chrysotile } & \multicolumn{2}{|c|}{ Control group 1} & \multicolumn{2}{|c|}{ Control group 2} \\
\hline No of rats examined & \multicolumn{2}{|c|}{36} & \multicolumn{2}{|c|}{39} & \multicolumn{2}{|c|}{36} & \multicolumn{2}{|c|}{25} \\
\hline Organ system & B & $\mathbf{M}$ & B & $\mathbf{M}$ & B & $\mathbf{M}$ & B & $\mathbf{M}$ \\
\hline Digestive/peritoneal & 1 & 1 & 1 & - & 1 & 3 & 1 & - \\
\hline Urinogenital & - & $\mathrm{i}$ & - & 1 & - & 2 & 2 & - \\
\hline Endocrine & 8 & $i$ & 5 & 2 & 6 & 2 & 3 & \\
\hline $\begin{array}{l}\text { Musculo, skeletal, and } \\
\text { integumentary }\end{array}$ & 1 & 2 & - & 6 & - & 5 & 2 & 3 \\
\hline $\begin{array}{l}\text { Reticuloendothelial/ } \\
\text { vascular }\end{array}$ & - & 4 & - & 3 & - & 3 & - & 1 \\
\hline Totals & 10 & 9 & 6 & 12 & 7 & 15 & 8 & 4 \\
\hline
\end{tabular}

$\mathbf{B}=$ Benign; $\mathbf{M}=$ malignant.

Table 6 Estimates of lung dust content of rats treated with charged and discharged chrysotile asbestos. (Figures in parentheses are standard deviations)

\begin{tabular}{lll}
\hline $\begin{array}{l}\text { Time after end of } \\
\text { dusting }\end{array}$ & Normal chrysotile & Discharged chrysotile \\
\hline 0 & $889 \mu \mathrm{g}(135)$ & $710 \mu \mathrm{g} \mathrm{(135)}$ \\
6 months & $315 \mu \mathrm{g} \mathrm{(49)}$ & $221 \mu \mathrm{g} \mathrm{(119)}$ \\
\hline
\end{tabular}

Figures quoted are the means of groups of four rats in each case.

hyperplasia on their pleural surfaces as described previously. ${ }^{20}$ In only one case, however, had a definite mesothelioma occurred.

There were no significant differences between the numbers of tumours found in organs other than the lung for the two groups of animals treated with chrysotile or the controls (table 5).

\section{LUNG DUST ANALYSIS}

The amounts of chrysotile asbestos recovered from rat lung tissue in this study are illustrated in table 6 . At the end of the dusting period, animals exposed to normally charged chrysotile had approximately $20 \%$ more retained dust than those exposed to discharged chrysotile. This difference is statistically significant $(p<0.01)$ (F-statistic 9.3 with 1 and $12 \mathrm{df}$ ). From the end of dusting the clearance of chrysotile from lung tissue was similar in both treatment groups with approximately $60 \%$ of dust being removed from the lung tissue over a six months period.

\section{Discussion}

In the present study rats were exposed to dust clouds of chrysotile asbestos either carrying a substantial electrostatic charge or discharged by passing through a thallium-204 source of $\beta$ particles before entering into the exposure chamber. Charge levels for the untreated dust cloud throughout the experiment were found to be about 13 electrons $/ \mu \mathrm{m}$ of fibre length and this was substantially lower than reported in previous short term deposition studies using the same techniques when charge levels of 20 electrons $/ \mu \mathrm{m}$ were reported. ${ }^{1213}$ The charge on airborne chrysotile fibres in these experiments was produced by the actions of the mechanical dust dispenser, compressed air, etc, and was, therefore, not under direct control. The difficulties of obtaining consistent effects in experiments with triboelectric and contact electrification under changing conditions of humidity are well known and some differences were not, therefore, unexpected, particularly as the earlier studies were conducted over a much shorter period than the present ones. Regardless of this, however, there was still a substantial difference between the charge levels present in the charged and discharged dust clouds which was quite sufficient to allow an examination of differences in long term dust pathogenicity resulting from the discharging process. In addition the levels of charge found in the present study were much closer to those reported for asbestos fibres in the working environment ${ }^{5}$ and this suggests that these experimental findings may be particularly relevant.

The differences in charge levels largely explain the lower differentials for dust deposition between the present long term studies and the previous short term ones. In 1983 it was reported that a $50 \%$ reduction of dust deposition occurred in rat lungs after the discharging of a cloud of UICC chrysotile when the original charge level had been 20 electrons $/ \mu \mathrm{m} .{ }^{13}$ At a charge level of 13 electrons $/ \mu \mathrm{m}$, the reduction in dust deposition has been found to be approximately $20 \%$. An added factor may have been the use of normal daylight dusting as has been usual for long term experimental pathology studies from this Institute ${ }^{19202526}$ whereas the short term studies were conducted using reversed daylight techniques. ${ }^{27} \mathrm{By}$ this administration of dust during the most active phase of the animal's life cycle it was shown that pulmonary dust deposition was substantially increased. In daylight dusting, however, the animal's 
low respiration rate may increase the chances of dust deposition by ordinary settlement and impaction and thus reduce the enhancement of deposition that can be caused by electrostatic forces. This effect has also been shown for people. ${ }^{8}$

Rats treated with discharged chrysotile had significantly less dust in their lungs at the end of a one year inhalation period than rats treated with chrysotile carrying substantial charge levels produced during the mechanical dispersion of the dust. Similarly, the rats treated with discharged chrysotile had lower levels of pulmonary fibrosis and fewer pulmonary tumours. Whereas with the group sizes available some of these differences were not statistically significant, the magnitude of the differences are such as would be expected if they were the direct consequence of the differences in dust deposition. These findings confirm that consideration of the charge on chrysotile fibres in the workplace is important, ${ }^{28}$ especially as the effects should be greatest for the long fibres which are the most pathogenic. ${ }^{29}$ Highly charged fibres, if they are inhaled, are more likely to be deposited in lung tissue and appear to produce higher levels of pulmonary disease in proportion to the increased lung dust burden.

This work was undertaken as part of the research programme sponsored by the British Asbestosis Research Council.

\section{References}

1 Bodenstedt E. Über die elektrische Aufladung augewirbelter Staubwolken. Zeitschuft für Angewandte Physik 1954;6: 297-303.

2 Walkenhorst W. Charge measurement at dust particles. StaubReinhaltung der Luft 1971;31:8-16.

3 Stein RL. Deposition of aerosols on a charged polystyrene surface. Am Ind Hyg Assoc J 1972;33:775-83.

4 Shevchenko AM. The role of some physical and chemical properties of mine dust in the development of pneumoconiosis. In: Walton WH, ed. Inhaled particles III. London: Unwin Bros, 1971:561-70.

5 Johnston AM, Vincent JH, Jones AD. Measurements of electrostatic charge for workplace aerosols. Ann Occup Hyg 1985;29:271-84.

6 Vincent JH. On the practical significance of electrostatic lung deposition of isometric and fibrous aerosols. Journal of Aerosol Science 1985;16:511-9.

7 Melandri C, Prodi V, Tarvoni G, et al. On the deposition of unipolar charged particles in the human respiratory tract. In: Walton WH, ed. Inhaled particles IV. Oxford: Pergamon Press, 1977:193-210.

8 Melandri C, Tarvoni G, Prodi V, De Zaiacomo T, Formignani M, Lombardi CC. Deposition of charged particles in the human airways. Journal of Aerosol Science 1983;14:657-69.

9 Prodi V, Mularoni A. Electrostatic lung deposition experiments with humans and animals. Ann Occup $H_{y}$ 1979;22:141-52.

10 Fraser DA. The deposition of unipolar charged particles in the lungs of animals. Arch Environ Health 1966;2:535-43.

11 Ferin J, Mercer TT, Leach LJ. The effect of aerosol charge on the deposition and clearance of titanium dioxide particles in rats. Environ Res 1983;31:148-51.

12 Vincent JH, Johnston WB, Jones AD, Johnston AM. Static electrification of airborne asbestos: a study of its causes, assessment and effects on deposition in the lungs of rats. Am Ind Hyg Assoc J 1981;42:711-21.

13 Jones AD, Johnston AM, Vincent JH. Static electrification of airborne asbestos dust. In: Marple VA. Liu BYH, eds. Aerosols in the mining and industrial work environment. Vol 2. Michigan; Ann Arbor Science 1983:613-32.

14 Beckett ST. The generation and evaluation of UICC asbestos clouds in animal exposure chambers. Ann Occup $\mathrm{H}_{l} \mathrm{~g}$ 1975; 18:187-98.

15 Timbrell V, Hyett AW, Skidmore JM. A simple dispenser for generating dust clouds from standard reference samples of asbestos. Ann Occup $H_{y g}$ 1968;11:273-81.

16 Dunmore JH, Hamilton RJ, Smith DSC. An instrument for the sampling of respirable dust for subsequent gravimetric assessment. Journal of Scientific Instruments 1964;41:669-72.

17 Asbestosis Research Council. The Measurement of airborne ashestos dust by the membrane filter method. Rochdale: ARC, 1971. (ARC technical note 1.)

18 Asbestosis International Association. Reference method for the determination of airhorne ashestos fibre concentrations at work places by light microscopy (membrane filter method). Recommended technical method no l. London: AIA, 1979.

19 Davis JMG, Beckett ST, Bolton RE. Collings P, Middleton AP. Mass and number of fibres in the pathogenesis of asbestosrelated lung disease in rats. Br J Cancer 1978:37:673-88.

20 Davis JMG, Addison J. Bolton RE, Donaldson $K$, Jones AD, Miller BG. Inhalation studies on the effects of tremolite and brucite dust in rats. Carcinogenesis 1985:6:66774.

21 Bolton RE, Vincent JH, Jones AD, Addison J, Beckett ST. An overload hypothesis for pulmonary clearance of UICC amosite fibres inhaled by rats. Br J Ind Med 1983;40:264-72.

22 Kaplan EL, Meier P. Non-parametric estimation from incomplete observations. Journal of the American Statistical Association 1958;53:457-81.

23 Dixon WJ, Brown MB. Engelman L, et al. BMDP statistical software. California: University of California Press, 1983.

24 Alvey NG, Banfield CF, Baxter RI, et al. GENSTAT. A general statistical programme. Rothamsted Experimental Station, 1977.

25 Davis JMG, Beckett ST, Bolton RE, Donaldson K. A comparison of the pathological effects in rats of the UICC reference samples of amosite and chrysotile with those of amosite and chrysotile collected from the factory environment. In: Wagner JC, ed. Biological effects of mineral fibres. Lyon: International Agency for Research in Cancer, 1982. (IARC sci publ No 30.)

26 Davis JMG, Addison J, Bolton RE, Donaldson K, Jones AD. Inhalation and injection studies in rats using dust samples from chrysotile asbestos prepared by a wet dispersion process. Br J Exp Pathol 1986;67:113-29.

27 Middleton AP, Beckett ST, Davis JMG. Further observations on the short-term retention and clearance of asbestos by rats using UICC reference samples. Ann Occup Hyg 1979;22:141-52.

28 John W, Vincent JH. Static electrification of workplace aerosols: a perspective. Ann Occup Hig 1985;29:285-8.

29 Davis JMG, Addison J, Bolton RE, Donaldson $K$. Jones AD, Smith T. The pathogenicity of long versus short fibre samples of amosite asbestos administered to rats by inhalation and intraperitoneal injection. Br J Exp Pathol 1986;67:415-30. 